Ya-Li Xue, Ai-Yun Zhang* and Dan Zhao

\title{
Crystal structure of catena-poly[octaaqua-bis $\left(\mu_{2-}\right.$ 4,6-dicarboxyisophthalate- $\mathrm{K}^{2} \mathrm{O}: \mathrm{O}^{\prime}$ ) cadmium(II) disodium(I)] dihydrate, $\mathrm{C}_{20} \mathrm{H}_{28} \mathrm{CdNa}_{2} \mathrm{O}_{26}$
}

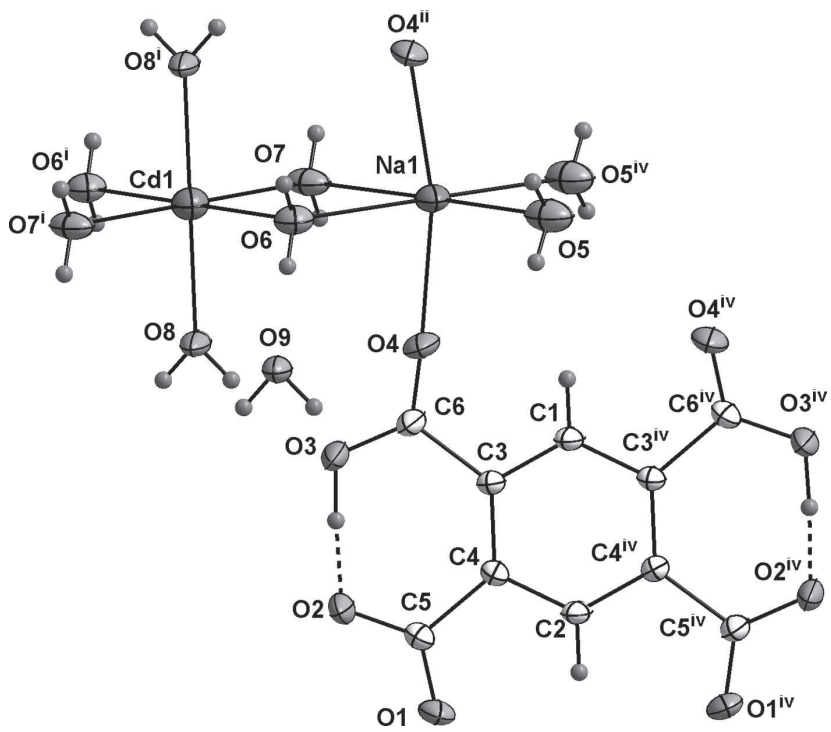

https://doi.org/10.1515/ncrs-2017-0349

Received February 4, 2018; accepted May 8, 2018; available online May 30, 2018

\section{Abstract}

$\mathrm{C}_{20} \mathrm{H}_{28} \mathrm{CdNa}_{2} \mathrm{O}_{26}$, monoclinic, $C 2 / m$ (no. 12), $a=7.4169$ (8) $\AA$, $b=20.183(2) \AA, \quad c=10.5403(11) \AA, \quad \beta=103.5520(10)^{\circ}$, $V=1533.9(3) \AA^{3}, Z=2, \quad R_{\mathrm{gt}}(F)=0.0434, \quad w R_{\mathrm{ref}}\left(F^{2}\right)=0.1271$, $T=296(2) \mathrm{K}$.

\section{CCDC no.: 1584515}

A part of the title crystal structure is shown in the figure. Tables 1 and 2 contain details on crystal structure and measurement conditions and a list of the atoms including atomic coordinates and displacement parameters.

*Corresponding author: Ai-Yun Zhang, College of Chemistry and Chemical Engineering, Henan Polytechnic University, Jiaozuo, Henan Province 454000, P.R. China, e-mail: zay@hpu.edu.cn

Ya-Li Xue and Dan Zhao: College of Chemistry and Chemical Engineering, Henan Polytechnic University, Jiaozuo, Henan Province 454000, P.R. China
Table 1: Data collection and handling.

\begin{tabular}{ll}
\hline Crystal: & Prism, colorless \\
Size: & $0.20 \times 0.05 \times 0.05 \mathrm{~mm}$ \\
Wavelength: & Mo $K \alpha$ radiation $(0.71073 \AA)$ \\
$\mu:$ & $0.85 \mathrm{~mm}^{-1}$ \\
Diffractometer, scan mode: & Bruker SMART, $\varphi$ and $\omega$-scans \\
$\theta_{\text {max }}$, completeness: & $28.5^{\circ},>99 \%$ \\
$N(h k l)_{\text {measured }}, N(h k l)_{\text {unique }}, R_{\text {int }}:$ & $9620,1988,0.044$ \\
Criterion for $I_{\text {obs }}, N(h k l)_{\text {gt }}:$ & $I_{\text {obs }}>2 \sigma\left(I_{\text {obs }}\right), 1714$ \\
$N(\text { param })_{\text {refined }}:$ & 121 \\
Programs: & Bruker programs [1], SHELX [2] \\
\hline
\end{tabular}

Table 2: Fractional atomic coordinates and isotropic or equivalent isotropic displacement parameters $\left(\AA^{2}\right)$.

\begin{tabular}{lrrrr}
\hline Atom & $\boldsymbol{x}$ & $\boldsymbol{y}$ & $\boldsymbol{z}$ & $\boldsymbol{U}_{\text {iso }}{ }^{*} \boldsymbol{U}_{\text {eq }}$ \\
\hline Cd1 & 0.0000 & 0.0000 & 0.0000 & $0.03157(19)$ \\
Na1 & $0.3202(3)$ & 0.0000 & $0.33009(18)$ & $0.0328(4)$ \\
C1 & 0.5000 & $0.1870(2)$ & 0.5000 & $0.0212(8)$ \\
H1 & 0.5000 & 0.1409 & 0.5000 & $0.025^{*}$ \\
C2 & 0.5000 & $0.3211(2)$ & 0.5000 & $0.0202(8)$ \\
H2 & 0.5000 & 0.3672 & 0.5000 & $0.024^{*}$ \\
C3 & $0.3971(4)$ & $0.21918(13)$ & $0.3901(3)$ & $0.0187(6)$ \\
C4 & $0.3970(4)$ & $0.28891(14)$ & $0.3900(3)$ & $0.0182(5)$ \\
C5 & $0.2960(4)$ & $0.33625(15)$ & $0.2837(3)$ & $0.0230(6)$ \\
C6 & $0.2959(4)$ & $0.17132(15)$ & $0.2848(3)$ & $0.0263(6)$ \\
O1 & $0.3071(3)$ & $0.39580(11)$ & $0.3048(2)$ & $0.0324(5)$ \\
O2 & $0.2042(4)$ & $0.31277(13)$ & $0.1771(2)$ & $0.0483(8)$ \\
O3 & $0.2040(5)$ & $0.19466(12)$ & $0.1763(3)$ & $0.0523(9)$ \\
O4 & $0.3040(4)$ & $0.11283(12)$ & $0.3051(3)$ & $0.0443(7)$ \\
O5 & $0.6633(6)$ & 0.0000 & $0.4355(4)$ & $0.0433(9)$ \\
O6 & $0.3102(5)$ & 0.0000 & $0.0920(3)$ & $0.0302(7)$ \\
O7 & $-0.0239(5)$ & 0.0000 & $0.2123(3)$ & $0.0339(8)$ \\
O8 & 0.0000 & $0.10786(16)$ & 0.0000 & $0.0470(11)$ \\
O9 & 0.5000 & $0.09711(15)$ & 0.0000 & $0.0294(7)$ \\
H8 & 0.0515 & 0.1361 & 0.0443 & $0.035^{*}$ \\
H5 & 0.7021 & -0.0310 & 0.3984 & $0.035^{*}$ \\
H9 & 0.4477 & 0.1264 & -0.0461 & $0.035^{*}$ \\
H6 & 0.3498 & 0.0317 & 0.0665 & $0.035^{*}$ \\
H7 & -0.0671 & -0.0326 & 0.2410 & $0.035^{*}$ \\
H3 & 0.1981 & 0.2450 & 0.1745 & $0.035^{*}$ \\
\hline
\end{tabular}

\section{Source of material}

A mixture of benzene-1,2,4,5-tetracarboxylic acid $\left(\mathrm{H}_{4} \mathrm{Btec}\right.$; $0.05 \mathrm{~g}), \mathrm{CdSO}_{4}(0.05 \mathrm{~g}), \mathrm{NaOH}(0.03 \mathrm{~g})$ and deionized water $(10 \mathrm{~mL})$ was placed in a $25-\mathrm{mL}$ Teflon-lined stainless steel 
autoclave. Then the autoclave was heated to $160{ }^{\circ} \mathrm{C}$ under autogenous pressure for $120 \mathrm{~h}$. After being slowly cooled to room temperature at a rate of $5{ }^{\circ} \mathrm{C} / \mathrm{h}$, colorless prismatic crystals were recovered by filtration, washed with distilled water and air dried.

\section{Experimental details}

The $\mathrm{C}$-bound $\mathrm{H}$ atom was positioned geometrically and refined with a riding model: $\mathrm{C}-\mathrm{H}=0.93 \AA$ with $U_{\text {iso }}(\mathrm{H})=1.2$. The water $\mathrm{H}$ atoms were located in the difference fourier maps, and then refined with $U_{\text {iso }}(\mathrm{H})=1.2 U_{\text {eq }}(\mathrm{O})$.

\section{Discussion}

A considerable amount of experimental data has been accumulated for the purpose of developing new coordination polymers with fascinating topology and interesting physical properties [3, 4]. Crystal engineering provides a powerful tool for the design and synthesis of novel compounds, and the advances in theory and practice of molecular crystallography have increased the speed and scope of structure determination enormously. Organic aromatic polycarboxylate ligands, as one kind of multi-dentate $O$-donor ligands have been extensively employed in the preparation of coordination polymer in possession of multi-dimensional networks and interesting properties [5, 6]. Taking these advantages into account, recently we have begun to assemble $\mathrm{H}_{4} \mathrm{btec}$, sodium ions and cadmium ions into polymeric complexes under hydrothermal conditions.

Single crystal X-ray analysis shows that the title compound exhibits a one-dimensional chain. This structure is isostructural to other reported compounds that the $\mathrm{Cd}^{2+}$ ions were substitued by $\mathrm{Co}^{2+}$ [7], $\mathrm{Zn}^{2+}$ [8], $\mathrm{Mn}^{2+}, \mathrm{Ni}^{2+}$ [9], $\mathrm{Cu}^{2+}$ [10] and $\mathrm{Mg}^{2+}$ [11]. There is one quarter of a $\mathrm{Cd}^{\mathrm{II}}$ atom, one half of a $\mathrm{Na}^{\mathrm{I}}$ atom, one half $\mathrm{H}_{2} \mathrm{Btec}$ ligand, four halfs coordinating aqua and one half of a lattice water in the asymmetric unit. Each $\mathrm{Na}$ atom is hexa-coordinated by $\mathrm{O}$ atoms including two carboxylate $\mathrm{O}$ atoms and four water $\mathrm{O}$ atoms for a distorted $\mathrm{NaO}_{6}$ octahedron with the $\mathrm{Na}-\mathrm{O}$ bond distances ranging from 2.292(2) to 2.563(4) A. The Cd atom also resides in a $\mathrm{CdO}_{6}$ octahedron with the $\mathrm{Cd}-\mathrm{O}$ bond distances ranging from 2.177(3) to 2.286(3) $\AA$. The $\mathrm{CdO}_{6}$ octahedra connect $\mathrm{NaO}_{6}$ octahedra via edge-sharing $\mathrm{O}$ atoms to from a chain of $\left[-\mathrm{NaO}_{6}-\mathrm{CdO}_{6}-\right.$ $\left.\mathrm{NaO}_{6}-\right]_{\infty}$, whose two sides are occupied by half deprotonated $\mathrm{H}_{2} \mathrm{Btec}$ ligands. There exists two intramolecular hydrogen bonds in each $\mathrm{H}_{2}$ Btec ligand with the two $\mathrm{O}-\mathrm{H}$ distances, $\mathrm{O} 2-\mathrm{H} 3=1.37 \AA$ and $\mathrm{O} 3-\mathrm{H} 3=1.02 \AA$.
Acknowledgements: This work was supported by the Science and Technology Research Project of Henan Province (No. 172102310678), the Key research project of Henan Province Office of Education (No. 17 A150013), the Fundamental Research Funds for the Universities of Henan Province (NSFRF170301), and the Program for Innovative Research Team of Henan Polytechnic University (T2018-3).

\section{References}

1. Bruker: APEX3, SAINT-Plus, XPREP. Bruker AXS Inc., Madison, WI, USA (2016).

2. Sheldrick, G. M.: SHELXT - Integrated space-group and crystal-structure determination. Acta Crystallogr. A71 (2015) 3-8.

3. Yan, D.; Mao, F.-F.; Ruan, T.-T.; Mao, J.-G.: Two tartratoborates with hybrid anionic groups from unusual condensation reactions. Dalton Trans. 46 (2017) 7361-7368.

4. Huang, S.-X.; Zhang, L.-H.; Ma, M.-J.; Dan, Z.: Crystal structure of diaqua-bis(5'-(pyridin-1-ium4-yl)-1H-[3,3'-bi(1,2,4triazol)]-2'-ide- $\left.{ }^{2} N-N^{\prime}\right)$ cobalt(II)-bis(5-(pyridin-4-yl-kN)$1 H, 1^{\prime} H-3,3^{\prime}$-bi(1,2,4-triazole)) octamolybdate-water (2/1/8), $\mathrm{C}_{27} \mathrm{H}_{33} \mathrm{CoMo}_{4} \mathrm{~N}_{21} \mathrm{O}_{19}$. Z. Kristallogr. NCS 232 (2017) 769-771.

5. Ma, F.-X.; Zhao, D.; Zhang, R.-J.: Crystal structure of poly[diaqua-bis $\left(\mu_{2}\right.$-hydroxy)-bis $\left(\mu_{4}-3,4,5,6\right.$-tetrachlorophthalato$\left.\mathrm{K}^{3} O, O^{\prime}: O^{\prime} ; \mathrm{K}^{2} O^{\prime \prime}: O^{\prime \prime \prime}\right)$ dilanthanum(III)], $\mathrm{C}_{8} \mathrm{H}_{3} \mathrm{Cl}_{4} \mathrm{LaO}_{6}$. Z. Kristallogr. NCS 232 (2017) 165-166.

6. Zhang, Y. Y.; Zhao, H.; Yang, E. C.; Liu, Z. Y.; Shang, Q.; Zhao, X. J.: Triazolate-based 3D frameworks and a 2D layer with centrosymmetric CU-7(II), CU-5(II), Cu-4(II) clusters and tunable interlayer/interchain compactness: hydrothermal syntheses, crystal structures and magnetic properties. Dalton Trans. 44 (2015) 5826-5836.

7. Karanović, L.; Poleti, D.; Bogdanović, G. A.; Spasojević-de Biré, A.: Disodium hexaaquacobalt(II) bis[dihydrogen 1,2,4,5benzenetetracarboxylate(2-)] tetrahydrate, Acta Crystallogr. C55 (1999) 911-913.

8. Wu, C. D.; Wu, D. M.; Lu, C. Z.; Huang, J. S.: Octaaquabis[dihydrogen 1,2,4,5-benzenetetracarboxylate(2-)] disodium(I) zinc(II) dihydrate, Acta Crystallogr. E57 (2001) $\mathrm{m} 253-\mathrm{m} 255$.

9. Fabelo, O.; Canadillas-Delgado, L.; Pasan, J.; Ruiz-Perez, C.; Julve, M.: Influence of the presence of divalent first-row transition metal ions on the structure of sodium(i) salts of 1,2,3,4-benzenetetracarboxylic acid $\left(\mathrm{H}_{4}\right.$ bta). CrystEngComm 8 (2006) 338-345.

10. Du, Z.-X.; Li, J.-X.; Qin, J.-H.: Crystal structure of catena(hexakis $\left(\mu_{2}\right.$-aqua)-diaqua-disodium(I)copper(II) bis $\left(\mu_{2}\right.$ dihydrogen-1,2,4,5-benzenetetracarboxylate- 0,0 )) dihydrate, $\mathrm{Na}_{2} \mathrm{Cu}\left(\mathrm{H}_{2} \mathrm{O}\right)_{8}\left(\mathrm{C}_{10} \mathrm{H}_{4} \mathrm{O}_{8}\right)_{2} \cdot 2 \mathrm{H}_{2}$ O. Z. Kristallogr. NCS 223 (2008) 105-106.

11. Zhao, D.; Liang, P.; Li, Y. F.; Qiu, S.; Ren, J. R. Poly[[hexa$\mu$-aqua-diaquabis $\left(\mu_{4}\right.$-dihydrogen benzene-1,2,4,5tetracarboxylato) magnesium disodium] dihydrate]. Acta Crystallogr. E68 (2012) m902. 